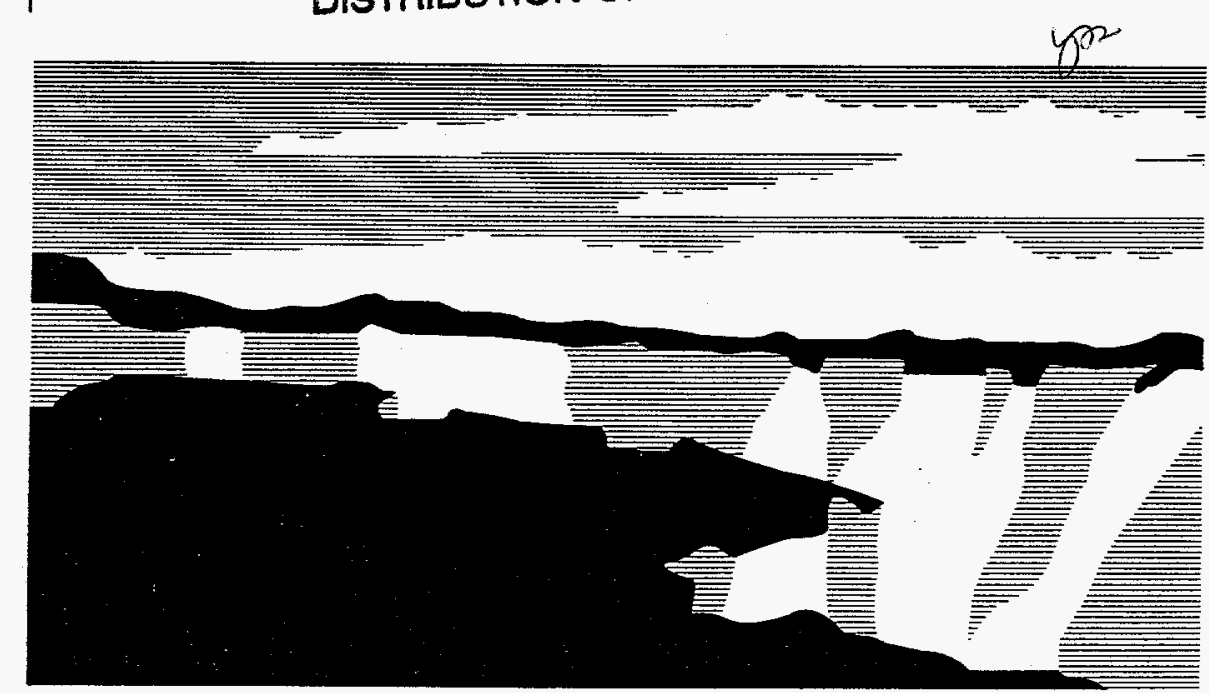

Los Alamos National Laboratory, an affirmative action/equal opportunity employer, is operated by the University of California tor the U.S. Department of Energy under contract W-7405-ENG-36. By acceptance of this article, the publisher recognizes that the U.S. Government retains a nonexclusive, royalty-free license to publish or reproduce the published form of this contribution, or to allow others to do so, for U.S. Government purposes. The Los Alamos National Laboratory requests that the publisher identify this article as work performed under the auspices of the U.S. Department of Energy. 
Log Nr. 108

\title{
ACCELERATOR-DRIVEN MOLTEN-SALT BLANKETS: PHYSICS ISSUES
}

\author{
Michael G. Houts, Carl A. Beard, John J. Buksa, J. Wiley Davidson, Joe W. Durkee, \\ R.T. Perry, and David I. Poston \\ Los Alamos National Laboratory \\ Los Alamos, NM 87545 \\ (505)665-4336 \\ Los Alamos National Laboratory \\ Los Alamos, NM 87545 \\ (505)665-4336
}

FINAL MANUSCRIPT prepared for:

Twelfth Symposium

on Space Nuclear Power System

Albuquerque, New Mexico

January 1995

DISCLAIMER

initial submission: June 1994

final submission: October 1994

This report was prepared as an account of work sponsored by an agency of the United States Government. Neither the United States Government nor any agency thereof, nor any of their employees, makes any warranty, express or implied, or assumes any legal liability or responsibility for the accuracy, completeness, or usefulness of any information, apparatus, product, or process disclosed, or represents that its use would not infringe privately owned rights. Reference herein to any specific commercial product, process, or service by trade name, trademark, manufacturer, or otherwise does not necessarily constitute or imply its endorsement, recommendation, or favoring by the United States Government or any agency thereof. The views and opinions of authors expressed herein do not necessarily state or reflect those of the United States Government or any agency thereof.

Author to whom correspondence should be sent:

Dr. Michael G. Houts

Los Alamos National Laboratory

Reactor Design and Analysis Group

Mail Stop K551

Los Alamos, NM 87545 


\section{DISCLAIMER}

Portions of this document may be illegible in electronic image products. Images are produced from the best available original document. 


\title{
ACCELERATOR-DRIVEN MOLTEN-SALT BLANKETS: PHYSICS ISSUES
}

\author{
Michael G. Houts, Carl A. Beard, John J. Buksa, J. Wiley Davidson, Joe W. Durkee, \\ R.T. Perry, and David I. Poston \\ Los Alamos National Laboratory \\ Los Alamos, NM 87545 \\ (505)665-4336
}

\begin{abstract}
A number of nuclear physics issues concerning the Los Alamos molten-salt, accelerator-driven plutonium converter are discussed. General descriptions of several concepts using internal and external moderation are presented. Burnup and salt processing requirement calculations are presented for four concepts, indicating that both the high power density externally moderated concept and an internally moderated concept achieve total plutonium burnups approaching $90 \%$ at salt processing rates of less than $2 \mathrm{~m}^{3}$ per year. Beginning-of-life reactivity temperature coefficients and system kinetic response are also discussed. Future research should investigate the effect of changing blanket composition on operational and safety characteristics.
\end{abstract}

\section{INTRODUCTION}

Accelerator-driven molten-salt blankets are being considered for numerous applications, primarily plutonium destruction and nuclear waste transmutation. Blanket safety and performance should be optimized for each application, as the blanket is a major component of the overall system, and optimal blanket design will vary with the purpose of the system. The overall safety and performance of any target/blanket (T/B) concept depends on the nuclear physics, thermalhydraulic, mechanical design, and other features of that system. The research reported in this paper focuses on the nuclear physics of subcritical molten-salt blankets designed for burning weapons-grade plutonium.

Two types of multiplying molten-salt blankets are under consideration: blankets with an internal graphite moderator and blankets with no internal moderator. These two concepts are used to highlight the important physics issues relevant to selecting a concept for conceptual design. Each blanket type has advantages and disadvantages. The difference in the performance of these two blankets is primarily caused by differences in neutron spectrum and neutron leakage. Specific physics issues used to compare these two concepts include safety, blanket multiplication, blanket reactivity temperature coefficients, attainable blanket plutonium burnup, blanket control, and blanket neutron spectrum.

In selecting one concept for further design, blanket control, maximum attainable burnup, and safety are used in the initial screening process. Engineerability, waste stream generation, and other factors are then used in the final selection process. Additional analyses are performed for point designs, including blanket flux distributions and the effect of various reactivity insertions. Reactivity insertion effects are evaluated by performing kinetics calculations that estimate blanket power, temperature, and reactivity throughout a postulated transient. Reactivity effects of cooling and over-temperature accidents are also evaluated, as are methods for ensuring blanket shutdown.

\section{TARGET/BLANKET DESCRIPTION}

As previously mentioned, two basic blanket arrangements were evaluated based on performance and safety. For both concepts, the T/B system consists of a molten lead target radially centered in 
the multiplying blanket, with the axial position optimized to produce the maximum effective number of neutrons for every incident proton. Salt enters at the bottom of the blanket and is pumped upward through the blanket. After exiting the active region, heat is transferred from the primary salt to a non-fissioning secondary salt. Various fission products are removed from the salt through an active helium gas sparge system and metal fission product plateout at the heat exchangers. The volume of the active region ranges from $2 \mathrm{~m}^{3}$ to $80 \mathrm{~m}^{3}$, depending on design specifics and whether external or internal moderation is used. The first configuration, termed internally moderated (IM), is very similar to the reactor core of the ORNL molten-salt breeder reactor (Robertson 1971). In this configuration the active blanket is comprised of $90 \%$ graphite and $10 \%$ molten fuel salt. Typical blanket dimensions are $5 \mathrm{~m}$ in diameter by $5 \mathrm{~m}$ tall, with the fuel salt traveling upwards through small (1- to 2-cm-diameter) circular channels cut directly into the graphite. A more detailed description of this concept can be found elsewhere (Venneri 1994 and Buksa et al. 1994). The second configuration, termed externally moderated, consists of an all-fuel salt core surrounded by a stainless-steel-clad graphite vessel. A schematic of this configuration is shown in Figure 1. The size of this T/B is roughly $1.4 \mathrm{~m}$ in diameter and $1.4 \mathrm{~m}$ tall.

\section{BURNUP}

Burnup analyses were performed for four design concepts using a coupled Monte Carlo neutronic (MCNP) and depletion code (ORIGIN2) system. The first concept is a reference internally moderated design, described in Robertson (1971). The active region for this concept has a volume of $80 \mathrm{~m}^{3}\left(8 \mathrm{~m}^{3}\right.$ of fuel salt), and consists of salt flowing through channels in graphite blocks. The second concept is a low power density, externally moderated system (LPD/EM). The active region for this concept is entirely fuel salt, and has a volume of $9 \mathrm{~m}^{3}$. A 1-m-thick graphite reflector surrounds the $T / B$, softening the neutron spectrum. The third concept is a high power density, externally moderated system (HPD/EM) with an active region (pure fuel salt) volume of $2 \mathrm{~m}^{3}$. The fourth concept is a low power density system with no graphite reflector (LPD/NM). The active region for this concept has a volume of $9 \mathrm{~m}^{3}$, and consists entirely of fuel salt.

In performing burnup calculations, several fission product classes are removed during operation, including noble gases ( $\mathrm{Kr}$ and $\mathrm{Xe}$ ), seminoble metals $(\mathrm{Zn}, \mathrm{Ga}, \mathrm{Ge}$, and $\mathrm{As}$ ), and noble metals $(\mathrm{Nb}, \mathrm{Mo}, \mathrm{Tc}, \mathrm{Ru}, \mathrm{Rh}, \mathrm{Pd}, \mathrm{Ag}, \mathrm{Cd}, \mathrm{In}, \mathrm{Sn}$, and $\mathrm{Sb}$ ). Maximum burnup is limited by reactivity and solubility considerations. Reactivity limits are caused by the need to maintain a specified blanket multiplication (based on accelerator size and other factors). Solubility limits are caused by the need to ensure that plutonium and lanthanides remain dissolved in the salt during all operating conditions. Two solubility limits were considered: $75 \%$ of the solubility limit at the lowest projected blanket operating temperature $(0.3$ moles/liter at $850 \mathrm{~K})$, and the solubility limit at the near freezing temperature of the salt $(0.1$ moles/liter at approximately $725 \mathrm{~K})$.

Table 1 gives a summary of the results for the four systems evaluated. Burnup and cycle time for each of the four systems are shown for three conditions: at a total plutonium and lanthanide concentration of 0.1 moles/liter, at a total plutonium and lanthanide concentration of 0.3 moles/liter, and at peak bumup or 10 full power years (FPY). Table 1 contains several interesting results. First, the LPD/EM and LPD/NM systems achieve significantly lower peak burnups than the other two systems. Second, the peak attainable single-pass burnup (without the use of supplemental fissile material) is quite high (90\%). Third, the IM and HPD/EM systems have very similar peak burnups, although this burnup is reached in less than half the time by the HPD/EM system. The decision on whether to use the IM or HPD/EM system will be made based on factors other than burnup. In Table 1, cycle time refers to the time at which the concentration limit is reached for the system.

Another parameter of interest is the salt processing requirement, summarized in Table 2 . The rate at which salt must be processed will effect operating costs and other parameters. As shown in 
Table 2, the required salt processing rate for the HPD/EM system is slightly lower than for the other systems, especially at peak burnup.
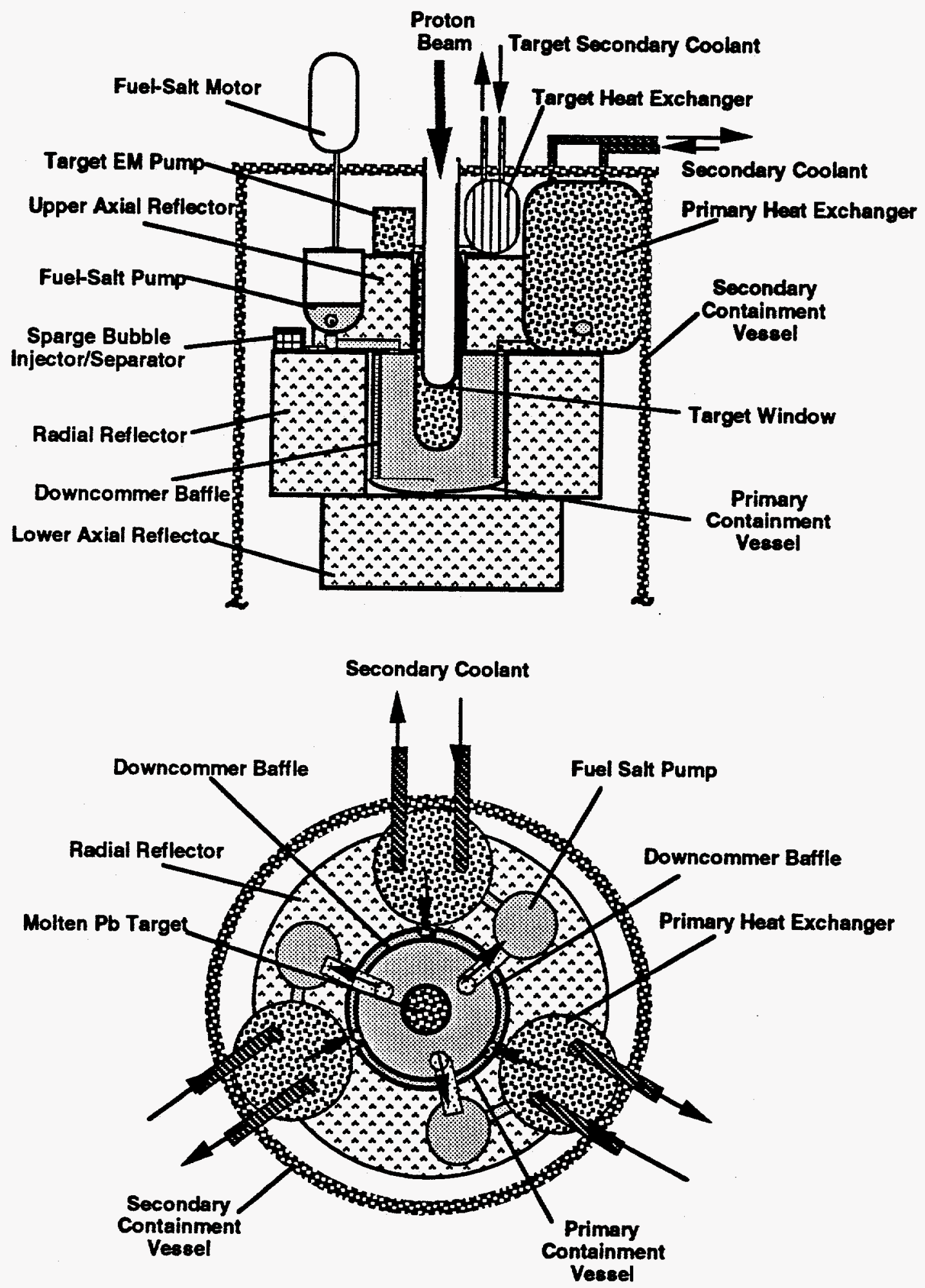

FIGURE 1. Sketch of Externally Moderated ABC/ATW Concept. 
TABLE 1. Summary of Plutonium Burnup and Cycle Time for the Four Cases Studied.

\begin{tabular}{|l|cccccc|}
\hline \multirow{2}{*}{ System } & \multicolumn{2}{|c|}{ At 0.1 mole/liter } & \multicolumn{2}{c|}{ At peak or 10 FPY } & \multicolumn{2}{c|}{ At 0.3 mole/liter } \\
\cline { 2 - 7 } & $\begin{array}{c}\text { Pu BU } \\
(\%)\end{array}$ & $\begin{array}{c}\text { Cycle } \\
\text { Time (yr) }\end{array}$ & $\begin{array}{c}\text { Pu BU } \\
(\%)\end{array}$ & $\begin{array}{c}\text { Cycle } \\
\text { Time (yr) }\end{array}$ & $\begin{array}{c}\text { Pu BU } \\
(\%)\end{array}$ & $\begin{array}{c}\text { Cycle } \\
\text { Time (yr) }\end{array}$ \\
\hline IM & 81 & 3.2 & 88 & 10 & -90 & $\sim 12$ \\
HPD/EM & 82 & 1.5 & 88 & 5.1 & 88 & 5.1 \\
LPD/EM & 76 & 2.3 & 80 & -5.5 & 78 & 7.1 \\
LPD/NM & 69 & 1.9 & 73 & $\sim 4.5$ & 73 & 6.0 \\
\hline
\end{tabular}

IM - Internally Moderated

EM - Externally Moderated

HPD - High Power Density

LPD - Low Power Density

TABLE 2. Summary of the Salt Processing Capacity Requirement for the Four Cases Studied.

\begin{tabular}{|l|ccc|}
\hline System & $\begin{array}{c}\text { At } 0.1 \text { mole/liter Salt } \\
\text { Processing }\left(\mathrm{m}^{3} / \mathrm{yr}\right)\end{array}$ & $\begin{array}{c}\text { Peak or 10 FPY Salt } \\
\text { Processing (m3/yr) }\end{array}$ & $\begin{array}{c}\text { At 0.3 mole/liter Salt } \\
\text { Processing (m3/yr) }\end{array}$ \\
\hline IM & 5.81 & 1.86 & 1.55 \\
HPD/EM & 5.33 & 1.57 & 1.57 \\
LPD/EM & 6.04 & 2.53 & 1.96 \\
LPD/NM & 7.31 & 3.09 & 2.32 \\
\hline
\end{tabular}

Salt Processing Capacity $=$ cycle time $\mathrm{x}$ salt volume

The average burnup attainable by molten-salt systems is significantly higher than that attainable by solid-fuel systems. While a solid fuel system can attain high burnups in a small percentage of the fuel elements, low-burnup elements must be used to maintain the desired reactivity of the system. Thus for a given stockpile of material average burnup is low. In contrast, a molten-salt system offers several methods for easily removing those fission products with a high neutron absorption cross section from the fuel. The better neutron economy of the molten-salt system allows it to achieve much higher average burnups than conventional solid-fuel systems. Fission product removal from solid fuels is possible, although it is a batch process that can reduce system availability and result in large waste streams.

\section{REACTIVITY TEMPERATURE COEFFICIENTS}

Another distinguishing factor between blanket concepts is the temperature coefficient of reactivity. This coefficient (RTC) will impact both safety and operation because if the RTC is either highly positive or highly negative, accidental criticality could result from overheating or overcooling accidents, respectively. The most desirable RTC is probably one that is near zero or slightly negative. Effects of burnup on the RTC are also very important as the composition of the fuel salt is changing as a function of operating history. This effect is currently being assessed.

The temperature coefficient of reactivity is strongly dependent on the neutron spectrum, making it dependent on plutonium concentration and the degree of neutron moderation. At the beginning of its life, the internally moderated system has a strong positive RTC, whereas the externally 
moderated systems have coefficients either near zero or negative. Temperature coefficients for the internally moderated system are as high as $+1.0 \mathrm{e}-4 \mathrm{dk} / \mathrm{k} / \mathrm{C}$, whereas temperature coefficients for systems with no additional moderator (internal or external) can be set at $-1.5 \mathrm{e}-4 \mathrm{dk} / \mathrm{k} / \mathrm{C}$ or below. The potential for maintaining a desired RTC throughout system life is one advantage of a molten salt system. The desired RTC can be maintained by adjusting the neutron spectrum, adjusting the fuel composition, through initial system design, and other methods.

\section{KINETICS}

Unlike critical systems, subcritical multiplying blankets require an extemal neutron source to produce significant power. If the external source (accelerator) is turned off, the fission power in the blanket rapidly drops, and the decay of fission products becomes the only significant source of heat. In the systems being studied, the accelerator beam can be removed from the target quite rapidly (milliseconds), enabling rapid shutdown of the subcritical multiplying system. No mechanical systems are required to remove the accelerator beam, and passive systems are used to make accelerator shutdown extremely reliable.

Kinetics calculations have been performed on several point designs, and several observations have been made. First, from a criticality safety standpoint, even large positive temperature coefficients are acceptable, as long as $k_{\text {eff }}$ does not approach unity at the maximum blanket temperature. Large positive temperature coefficients may also be acceptable from an overall safety standpoint if it is possible to rapidly remove the neutron source (by turning the accelerator off or directing the beam away from the target). However, from a safety and operational standpoint it appears most desirable to design a system with a near-zero or negative RTC. Scoping studies have shown that it is possible to design a system with a beginning-of-life RTC ranging from strongly positive to strongly negative. It may be possible to set the RTC at a desired value throughout the system life.

A subcritical-molten-salt system has several kinetics-related advantages over other types of systems. For example, in a flowing-fuel system a large fraction of the delayed neutrons are emitted outside of the active region, reducing the effective delayed neutron fraction. While this is not a concern in a subcritical system, it could be a serious safety concern in a critical system, especially if temperature coefficients are near-zero or positive. A loss-of-flow accident in a flowing-fuel system results in a reactivity insertion because the delayed neutrons are no longer lost, which is again not a concern for a subcritical system but a potential concern for a critical system. Subcritical systems have substantial safety advantages over critical systems if the RTC is zero or positive, or if the RTC is negative but large reactivity insertions (comparable in magnitude to the available negative feedback) are possible. Subcritical systems are also more tolerant to uncertainties in fuel composition and fuel quantity.

Subcritical multiplying blankets are characterized by a very benign response to reactivity insertion accidents. For example, in a plutonium-based multiplying blanket operating at a $k_{\text {eff }}$ of 0.96 , an instantaneous reactivity insertion of $5 \$$ results in an increase in blanket power of less than $40 \%$ (assuming negligible feedback), which could be accommodated until the neutron source was removed. In contrast, a reactivity insertion of $5 \$$ into a critical system could result in a severe accident, especially if there is no strong source of negative reactivity feedback. It should be possible to design a system that limits the maximum accidental reactivity insertion to values much lower than $5 \$$, in which case the response of the subcritical multiplying blanket would be even more benign. General comments concerning the response of subcritical systems to reactivity insertions can be found in Perry et al. (1994).

\section{CONCLUSIONS}


Accelerator-driven transmutation is a viable option for utilizing excess weapons plutonium. Two conceptual designs have been produced that allow plutonium burnups approaching $90 \%$ in a single pass. Plutonium extraction from the salt and other methods could be used to allow burnups exceeding $99 \%$. Considerable future physics research is required to further develop blanket designs, beginning with the study of blanket operating characteristics as a function of burnup.

\section{Acknowledgments}

This work was performed at Los Alamos National Laboratory, and funded by the United States Department of Energy.

\section{References}

Buksa, J.J. et al. (1994) "Conceptual Design of a Thorium Target for Molten Salt Transmutation Systems," presented at the 1994 International Conference on Accelerator-Driven Transmutation Technologies and Applications, Las Vegas, Nevada, July 25-29, 1994, Los Alamos National Laboratory, Accelerator Operations and Technology Division, AOT-DO, Los Alamos, NM 87545.

Perry, R.T. et al. (1994) "Kinetics of Accelerator Driven Devices," presented at the 1994 International Conference on Accelerator-Driven Transmutation Technologies and Applications, Las Vegas, Nevada, July 25-29, 1994, Los Alamos National Laboratory, Accelerator Operations and Technology Division, AOT-DO, Los Alamos, NM 87545.

Robertson, R.C. (1971) "Conceptual Design Study of a Single-Fluid Molten-Salt Breeder Reactor," Oak Ridge National Laboratory, Report No. ORNL-4541, June 1971.

Venneri, F. (1994) "Overview of ADTT Target/Blanket Configurations," presented at the 1994 International Conference on Accelerator-Driven Transmutation Technologies and Applications, Las Vegas, Nevada, July 25-29, 1994, Los Alamos National Laboratory, Accelerator Operations and Technology Division, AOT-DO, Los Alamos, NM 87545. 